Archived version from NCDOCKS Institutional Repository http://libres.uncg.edu/ir/asu/

\title{
Appalachľan
}

B O O N E, N O R T H C A R O L I N A

\section{Punishing Brady, Redeeming Brady: A Fantasy Theme Analysis Of Memes From The 2015 Deflategate Controversy}

\author{
By: Gregory Perreault and Patrick Ferrucci
}

\begin{abstract}
This research explores the memes from the 2015 Deflategate controversy shared via Twitter. Through the lens of Symbolic Convergence Theory (SCT), and its associated method of Fantasy Theme Analysis, these memes illustrate four distinct fantasies that led to their creation: a fantasy related to mistrust of corporate powers, a fantasy relishing in the punishment of one of the NFL's top football stars, a fantasy conceiving of Quarterback Tom Brady as an underdog hero, and a fantasy that conceives of Brady as a redeemed innocent. Most memes had a negative connotation rooted in the disposition theory of sports spectatorship, given that the "rules of the game" had been violated, regardless of the source, and this affects the vital, perceived "fairness" of the game. Overall, the memes showcase concern over the perceived heavy-handed enforcement by the NFL commissioner.
\end{abstract}

Gregory Perreault \& Patrick Ferrucci (2019). Punishing Brady, redeeming Brady: a fantasy theme analysis of memes from the 2015 Deflategate controversy, Atlantic Journal of Communication, 27:3, 153-168, DOI: 10.1080/15456870.2019.1610761. Publisher version of record available at: https://www.tandfonline.com/ doi/full/10.1080/15456870.2019.1610761 


\title{
Punishing Brady, redeeming Brady: a fantasy theme analysis of memes from the 2015 Deflategate controversy
}

\author{
Gregory Perreault (i) ${ }^{\mathrm{a}}$ and Patrick Ferruccib \\ ${ }^{a}$ Department of Communication, Appalachian State University, Boone, North Carolina, USA; ${ }^{b}$ College of Media, \\ Communication and Information, University of Colorado Boulder, Boulder, Colorado, USA
}

\begin{abstract}
This research explores the memes from the 2015 Deflategate controversy shared via Twitter. Through the lens of Symbolic Convergence Theory (SCT), and its associated method of Fantasy Theme Analysis, these memes illustrate four distinct fantasies that led to their creation: a fantasy related to mistrust of corporate powers, a fantasy relishing in the punishment of one of the NFL's top football stars, a fantasy conceiving of Quarterback Tom Brady as an underdog hero, and a fantasy that conceives of Brady as a redeemed innocent. Most memes had a negative connotation rooted in the disposition theory of sports spectatorship, given that the "rules of the game" had been violated, regardless of the source, and this affects the vital, perceived "fairness" of the game. Overall, the memes showcase concern over the perceived heavy-handed enforcement by the NFL commissioner.
\end{abstract}

The American football team the New England Patriots won a decisive 45-7 victory in the AFC championship game against the Indianapolis Colts in January 2015. Yet in the days that followed, several news organizations reported that the National Football League was investigating the Patriots for intentionally deflating footballs, which is prohibited under league rules.

In football, the Patriots are a popular and controversial team with a history of breaking rules allegedly - so it is unsurprising that the reaction to this investigation was explosive online (Castellano, 2015). The Internet erupted with commentary regarding Patriots quarterback Tom Brady, in particular, and quickly adopted the Twitter hashtag “\#Deflategate." In May 2015, the NFL released a report that found it "likely" that Brady knew that the balls had been deflated. The NFL suspended Brady for the first four games of the 2015-16 season, fined the franchise \$1 million and required the team to forfeit two draft picks over the following seasons. Brady appealed his portion of the decision and won in September 2015. The suspension was reversed in April 2016 and Brady announced that he would no longer appeal, but would accept the suspension.

Throughout the controversy, Twitter served as a medium to discourse the credibility of Brady and NFL commissioner Roger Goodell. In prior research, social media have been found to be a method through which a collective group can develop a shared storyline on an issue (Page \& Duffy, 2013; Page, Duffy, Frisby, \& Perreault, 2016). This often occurs through the use of shared visual images and video.

American football is collectively valued as a $\$ 74.8$ billion industry, with the average franchise valued at $\$ 2.3$ billion in 2016 (Gaines, 2016, September 15). The credibility of Brady and the NFL commissioner remains significant in that it ensures stability so that the game can be enjoyed (Keenan, 2014, September 13). Furthermore, football is more than just a game in America - it is

CONTACT Gregory Perreault $\otimes$ perreaultgp@appstate.edu Department of Communication, Appalachian State University, 245 Walker Hall, Boone, North Carolina 28608. 
entertainment that reflects societal passions and concerns. In fact, Edge (2012) argued that, in America, football has transcended simply being a sport but is now a religion, and devoted followers need to believe in its credibility. As such, scandals such as Deflategate challenged that credibility. Sports Illustrated legal analyst Michael McCann posited that Deflategate is "the most bizarre and intense sports controversy" in recent memory and a controversy that could permanently affect the league's credibility (McCann, 2016). Understanding the rhetorical vision of the public concerning Deflategate, as indicated through memes, helps reveal societal passions and concerns more broadly.

In the present study, the researchers conducted a theoretical treatment of the memes - photos and videos altered and repackaged through social media - that were disseminated throughout the Deflategate controversy, examining how storylines became reified through the sharing of visuals via social media. Applying the lens of Symbolic Convergence Theory (SCT) and its related method of Fantasy Theme Analysis (FTA), the Deflategate social media visuals shared from January 2015 to Brady's victorious appeal in September $2015^{1}$ were examined. While researchers collected social media visuals throughout the controversy, the vast majority of memes - and the vast majority of those widely shared - appeared during this time frame. These fantasy themes, or patterns, were indicative of a more basic rhetorical vision regarding Deflategate, one resulting in part from the 2015 context that regarding a broader social concern about enforcement in America society.

In particular, the Deflategate memes shared more than 1500 times were given a close analysis to indicate what they mean in regards to the identified patterns and what they indicate regarding society more broadly.

In the pages that follow, the present study will be rooted in the literature of sports and society and memes. Additionally, this paper will discuss the theory of symbolic convergence and it is applied through its method of fantasy theme analysis in order to clarify how it speaks to the concerns of this study.

\section{Literature review}

\section{Sports and society}

While to some sports may come across as a frivolous hobby of many men and women nationwide, sport has also been called a positive force in the culture of America, a force that catalyzes change (Rowe, 2007). For example, some have posited that sports have, in the past, alleviated racial tension and brought new ideas and diversity into American homes (Hartmann, 2000). In fact, many scholars have argued that we can best understand how society thinks and operates by simply studying the reactions and devotion to sport (Halone \& Billings, 2010).

This devotion to sports has been often conceptualized through the lens of disposition theory, which posits that fans' affiliation with a team or player can be seen as existing along a continuum of affect; ranging from intense disliking to intense liking (Bryant \& Raney, 2000; Zillmann, Bryant, \& Sapolsky, 1989; Zillmann, Paulus, \& Snyder, 1993). Audiences feel driven to follow a sport through an entertainment motivation (Gantz \& Wenner, 1991; Wenner \& Gantz, 1998), an eustress motivation a motivation emerging from the beneficial stress induced by the suspense in a sporting event (Bryant, Comisky, \& Zillmann, 1977), and an esteem motivation given that viewing sports has been shown to increase self-esteem (Wann \& Branscombe, 1995; Wann, Peterson, Cothran, \& Dykes, 1999).

This esteem may come from the experience of watching a team or player disparaged, providing the spectator a brief bit of glory in superiority (Wolff, Smith, \& Murray, 1934). Society generally provides for "strict observation of the 'rules of the game' and rule violations are met with prompt disapproval by participants and spectators alike" (Zillmann et al., 1989, p. 245). Sports rely heavily on the "moral notion of fairness" (p. 245) and "any transgression is promptly punished" (p. 251).

${ }^{1}$ In October 2015, the NFL officially appealed the ruling in favor of Brady, allowing the controversy to continue until Brady accepted the decision reversal in April 2016. However, by October 2015, the issue's popularity on social media dwindled. 
Hovden (2015) argued that if we can understand how people make sense of sporting information, we can make sense of how they view all information. In his study of sports information in Norway, he found that sports organizations typically receive news coverage that likens them to individuals, giving them more power than ever before; however, scholars need to take a critical look at how organizations operate and how people treat them. By understanding how people comprehend sports information, we can begin to understand how we comprehend our world in general. And in terms of memes, the popularity of memes can be seen as an indicator of how society feels about specific contemporary issues (Harlow, 2013). The use of memes, as a social media phenomenon, can be considered an extension of sports spectatorship in that it "meets all the criteria of a beneficial leisure activity" by relieving people from "boredom", "tensions", and providing for "personal development" (Zillmann et al., 1989, p. 250). Sports also offer a degree of catharsis in that tense to relieve annoyance induced physiological arousal and displaces hostile behavior (Bryant \& Zillman, 1977).

\section{Memes}

The term "meme" was coined in 1976 to describe the "gene-like infectious units of culture that spread from person to person" (Shifman, 2013, p. 362). Dawkins (1976) referred to it as a "unit of cultural transmission, or a unit of imitation" (p. 206). Memes are integral for understanding how people conceptualize the world in digital culture. Memes contain three dominant attributes. The first attribute of a meme is that it is viral - that is something shared and appreciated widely through social media (Shifman, 2013). Knobel and Lankshear (2007) note that although memes are shared on a small scale - person to person - their impact is large scale in that they shape the mindset, actions, and behavior of social groups. The second attribute of a meme is that they reproduce through "various means of imitation" (Shifman, 2013, p. 365). The term "meme" fittingly describes these imitations through connoting the biological process of "mimesis." The third attribute is that they are shared through a process of selection. Memes vary in their degree of fitness for their sociocultural environment. This fitness is determined by the degree to which the memes make the kind of appropriate appeals that cause a meme to be shared.

First, and perhaps most obviously, memes tend to be shared if they are entertaining (Brown, Bhadury, \& Pope, 2010). Another of those appeals is one of timeliness, according to Yang and Wang (2015). Yang and Wang (2015) noted that media tends to be shared if it makes use of topics, videos, and images that are already viral on social media. Emotional appeals are also successful in being shared if they use humor, violence, children, and celebrities (Golan \& Zaidner, 2008; Southgate, Westoby, \& Page, 2010). From the perspective of disposition theory, memes tend to be humorous in that they tend to involve characters who audiences feel comfortable being the subject of their humor in that the "response to humorous presentations critically depend on respondents affect disposition toward the protagonists involved" (Zillmann \& Cantor, 1976, p. 93).

Memes have a dominant audience that skews age 35 and below; and while social media sites differ in the user demographics and engagement, this largely reflects social media use over all ("Age distribution," 2018; Shifman, 2014). When social media users share a meme - in particular via Twitter - they do so for a few reasons: to agree with the original statement, to validate what others think, to indicate that they are aware of the conversation, to share information, or as an act of loyalty (boyd, Golder, \& Lotan, 2010). Less often, they share the image to critique it as well. This notion of meme sharing maps on to Hall's (2001) notion of symbol reading in encoding/decoding: that readers can indicate agreement with the visual, negotiate with the visual or challenge the visual (Hall, 2001).

In their research on viral sharing, boyd et al. (2010) argued that "retweeting can be understood both as a form of information diffusion and as a means of participating in a diffuse conversation. Spreading tweets is not simply to get messages out to new audiences, but also to validate and engage with others" (p. 1). 


\section{Symbolic convergence theory and fantasy theme analysis}

To explore the Deflategate controversy, this research was guided by Symbolic Convergence Theory (SCT) and its critical method Fantasy Theme Analysis (FTA). Through the lens of symbolic convergence theory, memes are equivalent of an inside joke in which you have to know the code to understand it. In other words, they are an indication of a shared worldview. Viral public images can tap into certain fantasies through the narrative constructed (Durand, [1970] 1983). SCT's emphasis on exploring the shared narrative in symbols makes it a useful theory to apply to the Deflategate memes. The fantasies explored in FTA appear as communication units; they are not merely subconscious (Bormann, Cragan, \& Shields, 2003). People like to dramatize experiences through shared stories that emerge from interactions with symbols (Bormann, 1972). Fantasy Theme Analysis identifies fantasy themes by looking at the communicated symbols and watching for a pattern in how they fit into broader categories. Through the process of chaining, these themes shape the symbolic reality for those involved in the storytelling process (Bormann, 1972).

The fantasy themes also culminate into a shared rhetorical vision (Simmons, 2014). The presence of a rhetorical vision suggests a degree of communitarianism among those involved in the storytelling process (Foss \& Littlejohn, 1986). The rhetoric identified tends to be based on the audience's experiences in popular culture and society. These associations assign meaning through "commonly known references, juxtaposition of elements and form conventions" (Page \& Duffy, 2013, p. 9).

Scholars have used SCT to identify the rhetorical visions in a wide variety of media texts. FTA identified racism and sexism in the shared social vision that emerged from the social media memes of Richard Sherman, a Seattle Seahawks player known for his colorful and provocative taunts, tweets, and interviews (Page et al., 2016). In the rhetoric of newspaper cartoon imagery in the ClintonLewinsky-Starr affair, metaphors, and allusions were used extensively and were important factors in creating the cartoons' imaginative language (Benoit, Klyukovski, McHale, \& Airne, 2001). Also in political memes, Page and Duffy (2013) applied FTA to social media memes in the 2012 presidential debates between Mitt Romney and Barack Obama, analyzing how the campaigns used the memes strategically to shape a vision of their campaign.

With this in mind, this study sought to address these two research questions:

RQ1: What were the most privileged fantasy themes that emerged from memes shared during the Deflategate controversy?

RQ2: What do memes shared during the Deflategate controversy imply about a shared rhetorical vision concerning Deflategate?

\section{Method}

The results that follow report on the findings of a fantasy theme analysis of social media memes regarding the Deflategate controversy. In this section, each fantasy theme is discussed in connection with the memes that evidence them. With each meme, evidence of chaining will be provided by indicating the number of impressions and shares via social media. The memes chosen for illustration will be the most chained memes, but in addition, we will also try to display a holistic view of the controversy as discovered via social media, as it had three distinct stages: (1) the announcement of the initial investigation, (2) the conclusion of the NFL investigation and charges against the Patriots, and (3) the September 2015 win in an appeal battle by Tom Brady. Each of these stages resulted in an Internet storm of Deflategate discussion and memes, as is demonstrated in the pages that follow. Memes were located via Twitter by using the "\#Deflategate" hashtag and also by searching "\#Deflategate" on Google. In initial searches, we found that \#Deflategate was the most salient search term for finding memes most likely to chain. Search terms such as \#TomBrady, \#Patriots, and \#NFL, 


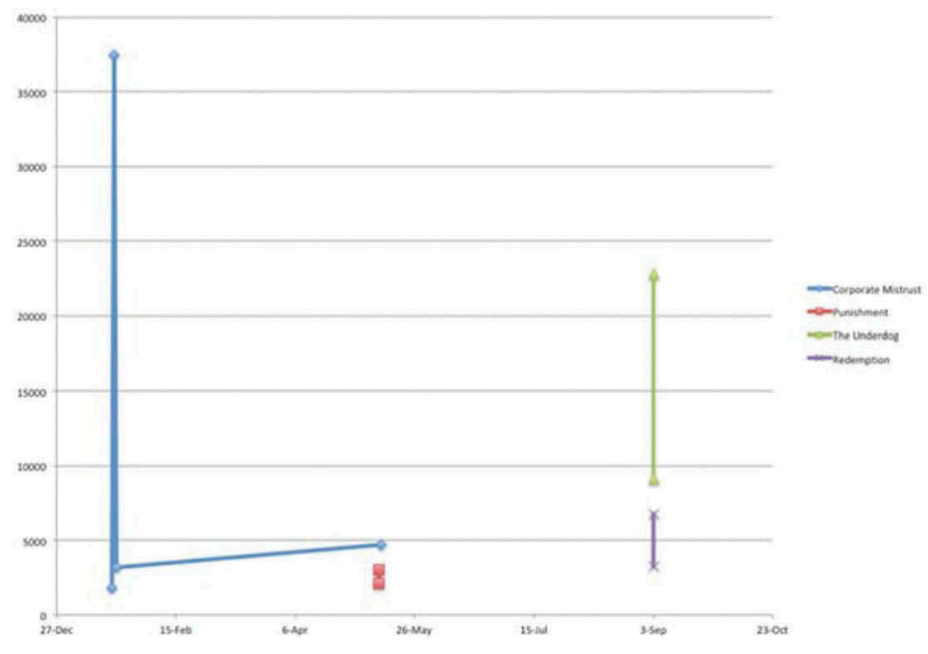

Figure 1.

for example, were too broad - the memes located under such terms were also less likely to chain. Some memes did not use the hashtag, even though the topic was explicit in the subject matter. By searching Google, it allowed us to locate additional, heavily circulated memes that were not readily available through the limited scope of Twitter's search utility.

The authors rooted themselves in the literature of sports and society and familiarized themselves with the background of Tom Brady and the Patriots prior to their analysis. Through a series of meetings, the authors reviewed all of the memes collected and narrowed the memes to the most retweeted images on Twitter. Then, the authors qualitatively explored each image through the fantasy theme analysis process of identifying protagonists, antagonists, plotlines, and settings (Foss \& Littlejohn, 1986). After collecting the data, the authors proposed fantasies that appeared most prominently in the images until they reached a consensus. Finally, those fantasies were reconnected to the individual memes and placed on the timeline of the controversy as it unfolded via social media (see the visual representation in Figure 1).

This study follows the time frame of the controversy from its beginning - after the American Football Conference (AFC) championship game on January 18, 2015 - to the appeal win on September 3, 2015. This research identified 18 distinct tweeted memes through Google search parameters and all were examined for the study. However, only images that chained through more than 1500 shares were included. In the findings, each of the fantasy themes is discussed with the relevant memes included.

\section{Findings}

In this research, we found four fantasies implicit in the memes shared throughout the early Deflategate controversy: a distrust fantasy, a punishment fantasy, an underdog fantasy, and a redemption fantasy. Each of these will be described in turn with a description of the relevant images.

As noted in the literature review, memes can be shared to indicate agreement with the visual, negotiate with the visual or to challenge the visual (boyd et al., 2010; Hall, 2001). These memes were shared by different types of people for a variety of reasons - in some cases the images speak to an audience defending Tom Brady, while others clearly attacked him. But the fact they were all shared indicates an underlying understanding of the symbols written into the meme - the "inside joke" in the imagery - and it is these symbols which indicate the deeper fantasy being transmitted in the images' chaining (Bormann, 1972). 


\section{Corporate distrust}

The first fantasy theme that emerged during data analysis consists of an implicit corporate distrust of the NFL. This theme presents itself primarily through memes mocking the severity of Deflategate. Shortly after the controversy erupted in January 2015, the Twitter account for Krispy Kreme donuts posted a meme of a deflated doughnut with the tagline: "Ours are fully filled" (see Figure 2).

Another meme, previewing the upcoming Super Bowl, showed a picture of the Lombardi Trophy, which is awarded to the Super Bowl winner, with a deflated football at the top. The tweet from CBS Sports Radio talk show host Jim Rome said, "This is what the Patriots are playing for. Allegedly" (see Figure 3). Finally, another meme depicted a photo of Tom Brady with a different uniform number and a crude mustache. Text on the meme said, "BREAKING NEWS: Patriots sign QB Jon Grady to a four-game contract. More details coming soon." The joke, retweeted by more than 5,000 people, tweaked both the Patriots and the NFL (Figure 4).

These three memes subtly illustrated a corporate distrust, to some degree of the NFL as a business. The Krispy Kreme meme and the "Jon Grady" meme both mock the severity of the case, one the NFL likened to serious rule breaking in early press conferences. These memes both implicitly argued that the matter, true or not, was not serious and did not deserve the type of attention it received. The Krispy Kreme meme, retweeted 2,294 times and favorited 2,226 times, told people that their doughnuts had the proper amount of cream in them, tacitly making the case that Deflategate was worthy of laughing at and, more than likely, a case of the NFL taking itself far too seriously and potentially misleading people. The Jon Grady meme, retweeted 5,089 times and favorited 4,810 times, mocks the issue even further, suggesting that both the NFL and the Patriots will go to any length to make sure one of their biggest stars is on the field despite a suspension. It also implies a profound distrust of the NFL, one that would let something as simple as a player donning a mustache, and a new number with a fake name gets back on the field without resistance.

Another meme, created by New England Patriots Tight End Rob Gronkowski, similarly makes fun of the Deflategate affair and indicates some distrust of the NFL commissioner (Figure 5).

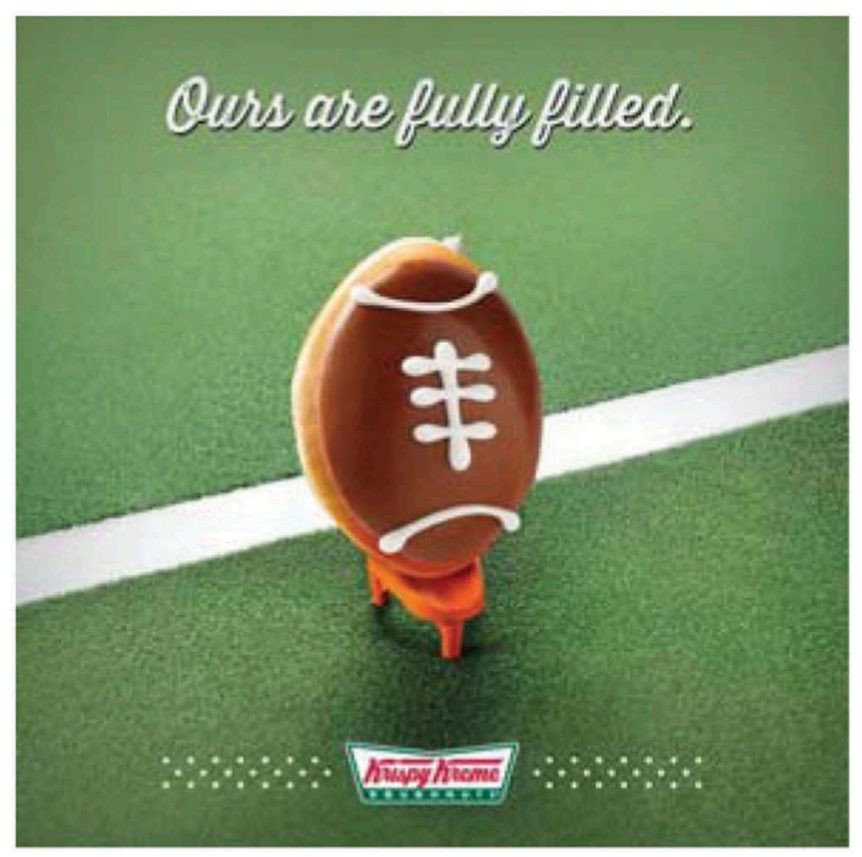

Figure 2. 


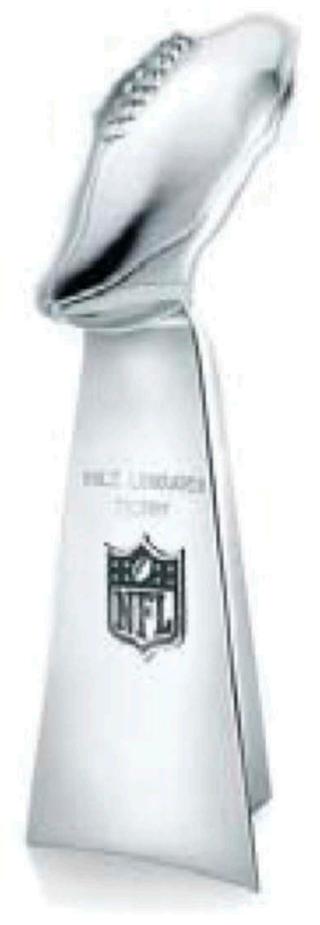

f @ijimrome

Figure 3.

In this meme, Gronkowski is shown spiking a football. The text overlaying the image reads "Warning, Gronking may cause deflation." Gronkowski's tweet accompanying the image reads "Whoops lol." The tweet, which was retweeted 40,698 times and favorited 39,139 times, argues that air pressure in footballs is a ridiculous topic for the NFL commissioner to investigate - footballs are thrown, kicked, and spiked throughout a football game. In short, this image indicates, there are a number of things, including weather that could have caused the decreased air pressure aside from intentional cheating by Tom Brady and the Patriots.

The final meme illustrating this fantasy theme came from sports journalist/personality Jim Rome, who tweeted out one with a deflated Lombardi Trophy and the text, "This is what the Patriots are playing for. Allegedly." First, the deflated trophy casts distrust concerning the NFL's champion, basically implying the winner of the game, if it was the Patriots, would not be a real champion (Figure 3). It implies a distrust of the NFL in that manner, but also of the Patriots. The meme, retweeted 1,940 times and favorited 1,302 times, is a clear joke, one that does not take itself too seriously, and the addition of the "allegedly" provides a little more formality to the critique. But it also subtly takes a swing at the NFL's honesty, basically acknowledging that the incident is either not a big deal or relatively fabricated into an issue to make news or take the focus off other issues. There were other issues that could have tarnished the NFL during the Super Bowl buildup, such as discussion of domestic violence and child abuse that occurred earlier in the season (Belson, 2015, November 10).

\section{Punishment}

Another fantasy theme identified excitement over the anticipated punishment of Tom Brady. Anyone who has followed a sports team knows that there are fans who need no excuse to ridicule a rival team. This is a darker fantasy that revels in seeing Tom Brady shamed and punished. 


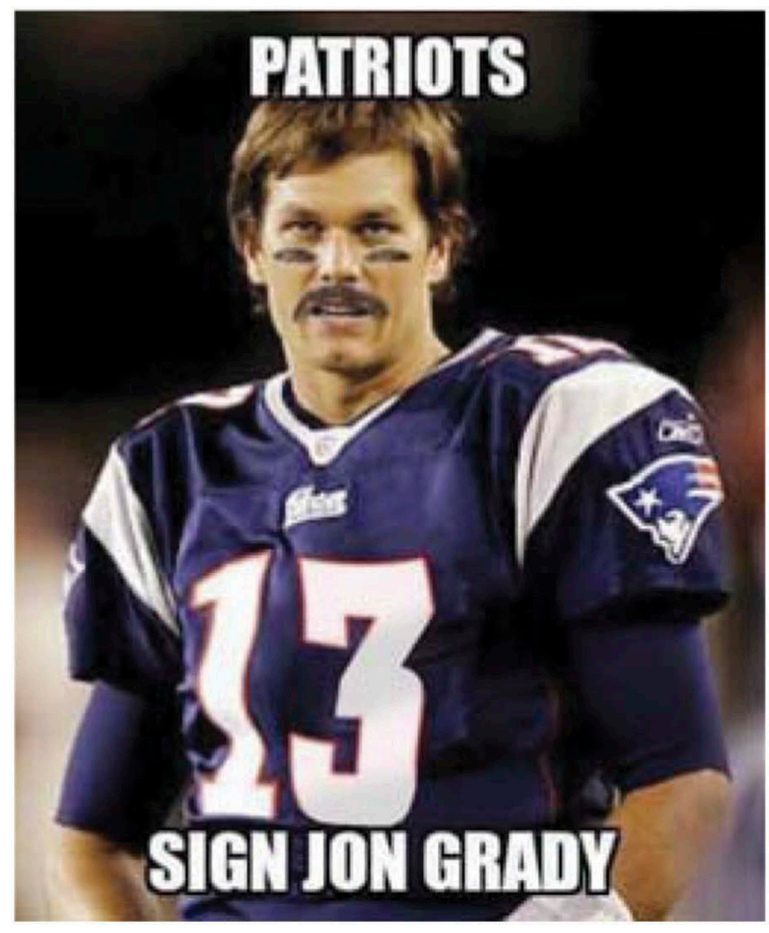

Figure 4.

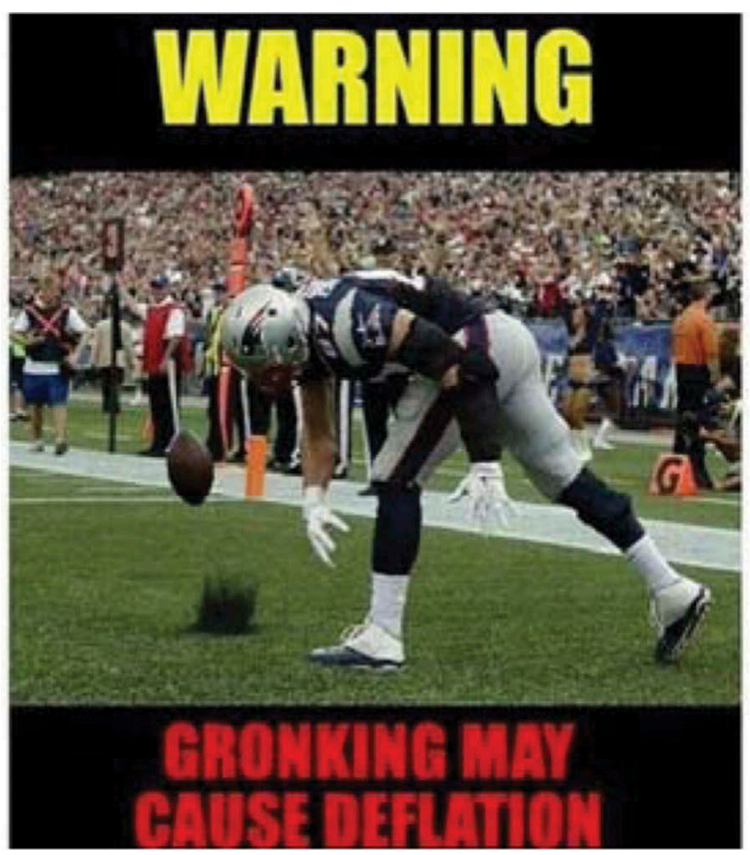

Figure 5. 


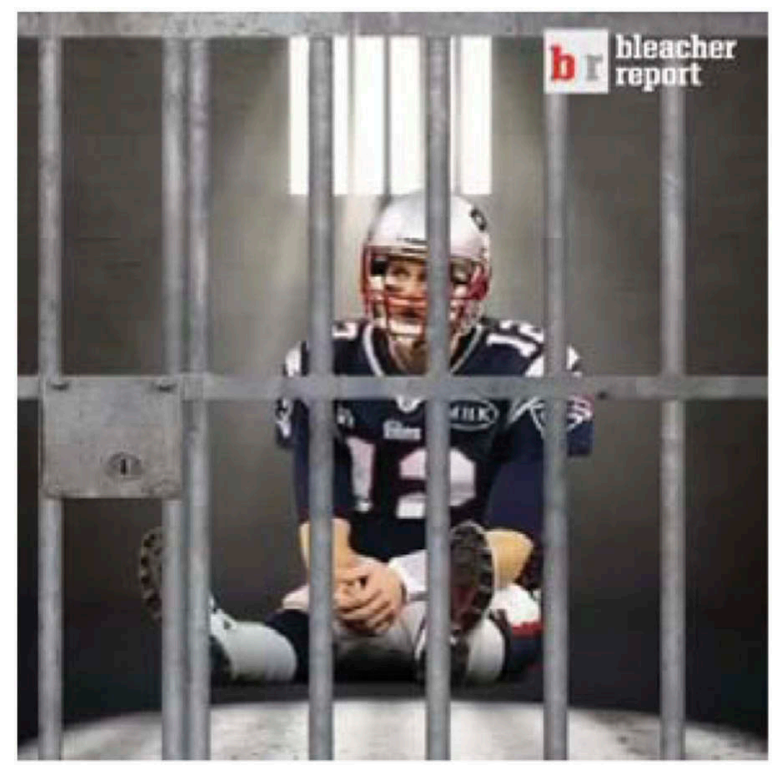

Figure 6.

The first meme, tweeted 2,278 times and favorited 2,079 times, was disseminated following the initial announcement of a four-game suspension for Tom Brady and the loss of draft picks for the Patriots. In this meme, Brady is in a jail cell with the cell door closing. He is wearing his football gear and is looking off camera morosely. The tweet accompanying the image read, "Do the crime. Do the time. \#Deflategate" (see Figure 6). The phrase is a reference to 1975 American television show Baretta, in which the singer in the theme song sings, "Don't do the crime if you can't do the time," This sort of popular culture reference is integral to how memes are created and why they tend to chain: They connect with the popular culture knowledge of their audience (Page \& Duffy, 2013).

Another meme seems to depict Brady as clueless, given the timing of its creation and distribution. Disseminated following the announcement of penalties against both Brady and the Patriots, this meme shows Brady holding the Lombardi Trophy and gesturing at the camera excitedly (see Figure 7). The tweet's text says “Tom Brady's response to his 4-game suspension." This image was retweeted 3,345 times and favorited 2,923 times. In this meme, Brady appears excited over his victory and yet ignorant of his punishment.

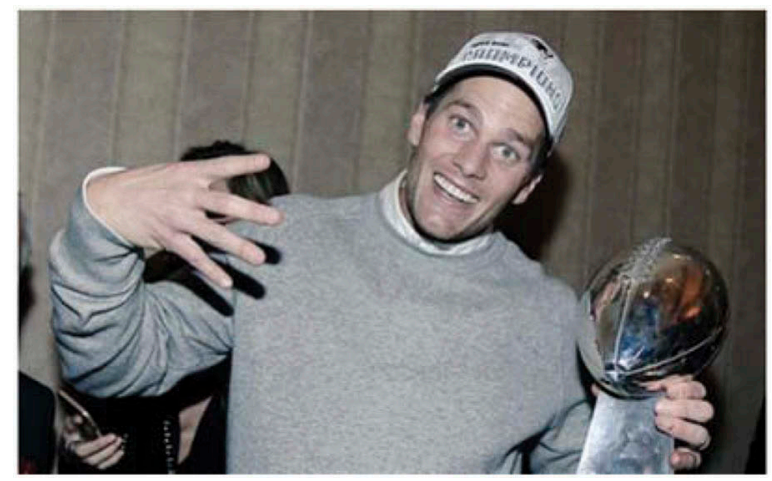

Figure 7. 


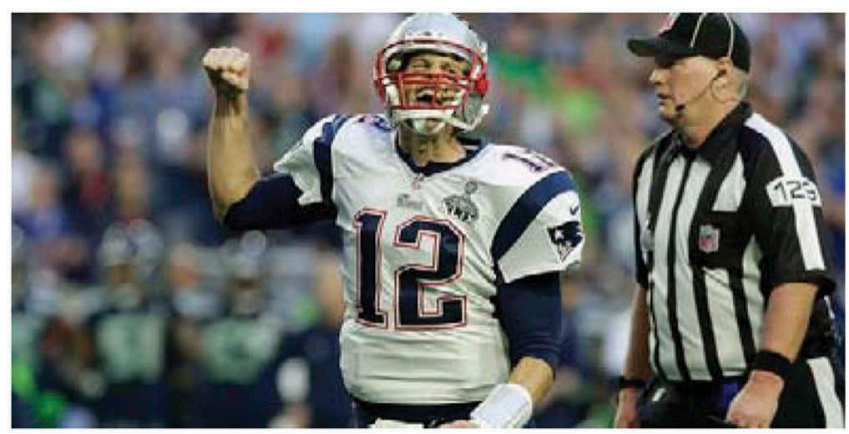

Figure 8.

\section{The underdog}

Another fantasy theme that emerged from the data was one of the underdog. This theme depicted Tom Brady as an underdog, trying to overcome the obstacles that stand in his path due to Deflategate. No NFL team thought Brady worthy enough of a draft pick until the Patriots selected him in the sixth round of the 2000 NFL Draft. Before that, he did not even consistently start for his college team, the Michigan Wolverines. Hence, the "underdog" is a theme often associated with Brady. These memes portrayed Brady not as the four-time Super Bowl champion with a multimillion-dollar contract and fame on and off the field, but as the player being tested by a goliath of sorts, the NFL.

One meme published first by the official Twitter account of the Patriots and retweeted more than 24,885 times and favorited 20,587 times saw Brady pumping his first next to a referee in a moment of sheer excitement. As the referee looks on, Brady is celebrating so strongly that his helmet looks like it may fly off at any moment, only the chin guard barely holding it on (see Figure 8). The referee looking on represents power, as he controls the flow and pace of the game and, specifically, enforces the rules Brady is accused of breaking. Brady's celebration could be seen as someone overcoming the obstacles in front of him and succeeding, all the while being watched by people in power, here represented by the referee but potentially also by the NFL.

The other reading of this specific meme is that Brady is succeeding at his sport. He may be counted out sometimes, but he comes through in the end. This meme first gained traction in early September, after the overturning of his suspension, and as such, it communicates that in the face of a large conglomerate, and even as an underdog, Brady still managed to succeed.

This fantasy presented itself in another widely shared meme. This meme depicts Brady dancing at the Super Bowl after party following the Patriots victory over the Seattle Seahawks in early 2015 (Figure 9). This gif was retweeted 13,099 times and favorited 8,344 times. The video shows a borderline giddy Brady awkwardly dancing and celebrating with a teammate. Once again disseminated just after a judge overturned his suspension, this meme displays Brady as an awkward underdog, one who is not as polished as he could be, but one who is still fighting - and winning. It shows that although things may have looked grim and that Brady looked like an underdog, he still overcame and ended up victorious, something that occurs often in Brady's life, according to these memes.

\section{Redemption}

Similar to the Underdog fantasy theme, the Redemption fantasy emerges from a public perception that sees Deflategate as having dragged on and the judgments against Tom Brady as being excessive. Overall, this fantasy derives from exhaustion with Deflategate and a desire to see Tom Brady as 




Figure 9.

a hero. The key feature differentiating this theme from the Underdog fantasy theme is the likening of Tom Brady to popular culture characters who have been redeemed in some way.

The most obvious example of this fantasy theme is through a meme referential to the movie Shawshank Redemption (Figure 10). In this meme, Tom Brady's face is transposed over that of the fictional movie character Andy Dufresne and Bill Bellicheck's face over the movie character Red. The



Figure 10. 




Figure 11.

image was retweeted 7,485 times and favorited 6,549 times. The text of tweet simply reads "Tom Brady is free." In the movie Shawshank Redemption, Andy Dufresne is a character who maintains his innocence in the murder of his wife despite being ruled as guilty and sentenced to life in prison. After approximately 20 years in Shawshank prison, Dufresne escapes and in the process sheds light on the corruption at the prison. In a parallel manner, this meme sees Tom Brady as a hero whose name has been slandered and he has been judged as guilty. Yet Brady maintained his innocence throughout the appeals process and even into his 2016 suspension.

Similarly, in Figure 11, a meme references the movie Good Will Hunting about a troubled but brilliant Boston laborer named Will Hunting, who works through his troubles through the help of a therapist. In the scene referenced in this image, Will Hunting competes for the attentions of a girl and gets her number. Later, he presses the number, written on the napkin, against a diner window to show his rival asking, "Do you like apples? Well, I got her number - how do you like them apples?" This image transposes Tom Brady's face over that Will Hunting and Roger Goodell - the commissioner of the National Football League - over that of Hunting's rival. The napkin in Brady's hand says "zero games," a reference to the fact that Brady will not have to be removed from any games with his team the following season as a result of the successful appeal. The text of the tweet, written to mimic a Boston accent, reads "HEY RAWDJAH." It was retweeted 3,468 times and favorited 2,541 times.

\section{Discussion}

In the findings section, we addressed the first research question regarding the fantasy themes that chained during the Deflategate controversy. We found four distinct fantasy themes that chained. The corporate distrust fantasy treated the topic lightly, as a cynical mockery more than anything else. The punishment fantasy gloried in the shaming of Brady - suspending him from games. The underdog fantasy saw Tom Brady as a hero who managed to succeed even up against a powerful league commissioner. And finally, the redemption fantasy saw Tom Brady as a figure who maintained his innocence through months of attack and then finally was very publicly redeemed - for a time, at least. The final two fantasies are similar but with the noteworthy difference that the underdog fantasy largely depicted Tom Brady as himself whereas the redemption fantasy largely likened Brady to other popular culture figures: Will Hunting and Andy Dufresne, in particular.

We noted that these fantasies largely mapped onto the three phases of the controversy. The playful distrust fantasy dominated in the memes shared in the weeks following the AFC Championship game against the Indianapolis Colts. When the initial ruling against Brady and the Patriots came down, the punishment fantasy was most common. Then, in the wake of the successful appeal, the majority of the memes fit in line with either the underdog or the redemption fantasy (see 
Figure 1). This progression of these fantasies is noteworthy in consideration of the shared rhetorical vision.

A negative bent emerged in these fantasies, which aligns with prior research in disposition theory. Corporate mistrust, punishment, and even the redemption fantasy all had an underlying concern that the fairness of the game had been violated and hence was met with "prompt disapproval" (Zillmann et al., 1989, p. 245). In the redemption fantasy, from this lens, the desire to punish Brady, the Patriots, and eventually Roger Goodall, in the redemption fantasy, is then a result from a desire to preserve the "rules of the game" (p. 245). The sharing of memes is motivated not just by their entertaining quality (Wenner \& Gantz, 1998), but also potentially by the feeling of superiority of audiences who could observe the controversy with the conviction that they had not broken the rules (Wolff et al., 1934).

Our second research question concerned the nature of the shared rhetorical vision regarding the Deflategate controversy. This shared rhetorical vision is composed of two dominant elements: the first is a desire for closure and this is evidenced through the progression of the phases. In the first phase, there was already a distrust of the commissioner and NFL in general. The lighter tone of these memes indicates that there was a shared perception that the investigation was a "joke" on a level with the memes shared. A perfect example of this is in the Gronking meme (Figure 5), which subtly pointed out that there are a number of factors that could cause the decreased air pressure in a football. In short, making a case for deliberate, malevolent action by Tom Brady would be difficult. In the second phase, the memes gloried in the punishment of Tom Brady, but they all carried an implicit finality. In the "Do the Crime, do the time" meme (Figure 6), there is, of course, a narrative finality to the slamming of a jail cell door. Even the clueless meme (Figure 7) indicates that Tom Brady will just go on playing football - he is a four-time Super Bowl champion and a four-game suspension is hardly a punishment that will keep him from continuing to play football. In the final phase, the redemption fantasy and the underdog fantasy both indicate that a hero has come through opposition to the other side. It is an artificial closure, of course, in that the NFL did eventually pursue the case and force a four-game suspension on Brady after the social media storm died down. But the memes provide a sense of closure that was not there. This desire for closure in the rhetorical vision makes sense, in that the Deflategate controversy took attention from what most people appreciate about football, which is the game itself.

The second element of the rhetorical vision was a tendency to link the controversy to popular culture. For example, in Figure 6, the tweet included a reference to the 1975 show Baretta. Similarly, in Figures 10 and 11, the memes contained even more explicit references to The Shawshank Redemption and to Good Will Hunting, respectively. These are, of course, all entertainment media. While it is in the nature of memes to imitate and repackage, in particular, by using shared cultural references (Page \& Duffy, 2009; Shifman, 2013), the use of these elements emphasize the frivolous nature of the entire investigation. The shared vision of Deflategate was that the controversy was just another form of entertainment - albeit perhaps less entertaining than the football itself.

This study builds on extant literature on sports and society by indicating the degree to which social media users were less invested in the regulation of the sport than with the entertainment derived from the sport itself. Deflategate was a disruptive event for the social media audience and, just as in the shared rhetorical vision, there was a desire to see Deflategate affair "closed" almost as soon as it was open. Similarly, there was a desire, throughout, to find some entertainment in the exaggerated nature of the controversy. Halone and Billings (2010) argued that we can understand how society thinks and operates by simply studying devotion to sport. With that in mind, this may indicate a broader societal concern regarding regulations and their enforcement in America.

In essence, while it might seem trivial to analyze a series of memes about a sports controversy, prior research illustrates why memes are so important to understanding how society processes and opinionates about popular news topics (i.e., Page \& Duffy, 2009; Page et al., 2016). Capturing the essence of popular shared memes, particularly ones that chain, tell us more than just what people think about a particular subject, but about how people think about the world as a whole (Shifman, 
2013). With Deflategate, a clear narrative emerged. People, almost regardless of fandom, rebelled against power, which in this case came in the form of the corporate NFL and its commissioner seemingly overstepping its limits and this could be seen here in the corporate distrust memes. Of course, this did not stop some from reveling in the negative circumstances surrounding one of the league's least-liked teams. The punishment fantasy theme illustrated this. But then, when examining themes, it became clear that while some did celebrate Brady and the Patriots' punishments, many also found excitement, hope, and enjoyment out of the team's potential victory over the NFL. This can be seen through both the underdog and redemption memes. What this shows, generally, is that, in America, corporate power can turn anyone, even a much-disliked franchise player and multimillionaire such as Tom Brady into an underdog. People tend to take the side of the regular person, not the people in power. And, more specifically, the trending of Deflategate memes once again shows the power of narrative. This story was only trending on social media until people found a conclusion. Even after Brady's suspension was reinstated and the Patriots were forced to play without for four games to start their 2016 season, Deflategate became a topic often ignored compared to its early days. This could be a lesson for how corporations go about public relations. There is a chance the NFL could have avoided much of the negative publicity surrounding the scandal by just thinking about how its actions would play out amongst regular fans.

Considering contemporary concerns regarding American policing (Hendricks, Kelley, Gordon, \& Foley, 2015), it would make sense that this same societal disposition would come out in American sports. During the time frame of Deflategate, American culture continued to talk about the issues of racial inequality regarding the operation of law enforcement and the militarization of the police force - much of it springing from the shooting of an unarmed black youth in Ferguson, Missouri, that occurred months befoDeflategate (Newburn, 2014). During the time frame of Deflategate, confidence in police hit its lowest point in 22 years, according to a Gallup poll (Jones, 2015). In a similar manner, Americans also reported the lowest reported trust of government in half a century (Pew, 2015) and reported that nearly half of Americans see corporations as a "source of fear" (Lam, 2014). With the much more serious issues of authority, racial inequality and law enforcement taken into account, this places the comparatively frivolous affair of Deflategate into sharp contrast. But it also indicates a potential root for the distrust of the NFL and a root for the frustration with the perceived heavy-handed nature of rule enforcement in the NFL.

This research also builds on symbolic convergence theory by modeling how societal concerns emerge out of two seemingly "light" mediums (Bormann, 1972). Few would think to look to sports and to sports memes as a place where societal concerns about sports regulation might emerge, but that is precisely what was found. It is worth considering the media that entertain us, entertain us for a reason - because they are a reflection of the things we cheer for, that we fear, and that drive us to work for a better world.

\section{Limitations and avenues for further research}

As evidenced by the theoretical framework of this study, this research emerges from the interpretivist tradition and, as such, no claims can be made as to the generalizability of the study. There is no need for replication of research in a culturalist study such as this, in that the researchers are assumed to be a central part of the research process (Hesse-Biber, 2010); however, it should be noted that researchers compared findings and arrived at a shared interpretation of the data. Similar research on scandals in the NFL (i.e., Page et al., 2016) showcase how sports media shed light on larger issues in society. Future research would benefit from additional analysis regarding how this occurs and what it is about sports that make it such an effective medium for reflecting contemporary concerns.

\section{Disclosure statement}

No potential conflict of interest was reported by the authors. 


\section{ORCID}

Gregory Perreault (D) http://orcid.org/0000-0002-6645-1117

\section{References}

"Age distribution of active social media users worldwide as of 3rd quarter 2014, by platform." (2018, May 3). Statista. Retrieved from https:/www.statista.com/statistics/274829/age-distribution-of-active-social-media-users-worldwideby-platform/

Belson, K. (2015, November 10) Domestic violence is a reoccurring quandary for the N.F.L. The New York Times. Retrieved from http://www.nytimes.com/2015/11/11/sports/football/domestic-violence-is-a-recurring-quandary-for -the-nfl.html?_r=0

Benoit, W., Klyukovski, A., McHale, J., \& Airne, D. (2001). A fantasy theme analysis of political cartoons on the Clinton-Lewinsky-Starr affair. Critical Studies in Media Communication, 18(4), 377-394. doi:10.1080/ 07393180128097

Bormann, E., Cragan, J., \& Shields, D. (2003). Defending symbolic convergence theory from an imaginary Gunn. Quarterly Journal of Speech, 89, 366-372. doi:10.1080/0033563032000160990

Bormann, E. G. (1972). Fantasy and rhetorical vision: The rhetorical criticism of social reality. Quarterly Journal of Speech, 58(4), 396-407. doi:10.1080/00335637209383138

boyd, D., Golder, S., \& Lotan, G. (2010, January). Tweet, tweet, retweet: Conversational aspects of retweeting on Twitter. Paper presented at the meeting of the International Conference on System Sciences, Hawaii.

Brown, M. R., Bhadury, R. K., \& Pope, N. K. L. (2010). The impact of comedic violence on viral advertising effectiveness. Journal of Advertising, 39, 49-65. doi:10.2753/JOA0091-3367390104

Bryant, J., \& Raney, A. A. (2000). Sports on the screen. In D. Zillmann \& P. Vorderer (Eds.), LEA's communication series. Media entertainment: The psychology of its appeal (pp. 153-174). Mahwah, NJ, US: Lawrence Erlbaum Associates Publishers.

Bryant, J., Comisky, P., \& Zillmann, D. (1977). Drama in sports commentary. Journal of Communication, 27(3), 140-149. doi:10.1111/j.1460-2466.1977.tb02140.x

Bryant, J, Comisky, P, \& Zillmann, D. (1977). Drama in sports commentary. Journal Of Communication, 27(3), 140149.

Castellano, A. (2015, January 21). Deflate-gate and other New England Patriots controversies. ABC News. Retreived from http://abcnews.go.com/Sports/deflate-gate-england-patriots-controversies/story?id=28373420

Dawkins, R. (1976). The selfish gene. Oxford, England: Oxford University Press.

Duffy, M. E, \& Page, J. T. (2013). Does political humor matter? you betcha! comedy tv's performance of the 2008 vice presidential debate. The Journal Of Popular Culture, 46(3), 545-565.

Durand, J. ([1970] 1983). Rhetoric and the advertising image. Trans. Theo van Leeuwen. Australian Journal of Cultural Studies, 2(1), 29-61.

Edge, A. (2012). Faith of our fathers: Football as a religion. New York, NY: Random House.

Foss, K. A., \& Littlejohn, S. W. (1986). The day after: Rhetorical vision in an ironic frame. Critical Studies in Media Communication, 3(3), 317-336.

Gaines, C. (2016, Sept. 15). The 32 NFL teams are worth as much as every MLB and NBA team combined. Business Insider. Retrieved from http://www.businessinsider.com/nfl-teams-value-2016-9

Gantz, W., \& Wenner, L. A. (1991). Men, women, and sports: Audience experiences and effects. Journal of Broadcasting \& Electronic Media, 35(2), 233-243. doi:10.1080/08838159109364120

Golan, G. J., \& Zaidner, L. (2008). Creative strategies in viral advertising: An application of Taylor's six-segment message strategy wheel. Journal of Computer-Mediated Communication, 13, 959-972. doi:10.1111/jcmc.2008.13. issue-4

Hall, S. (2001). Encoding/decoding. In M. Durham \& D. Kellner (Eds.), Media and cultural studies: Keyworks. New York, NY: Wiley-Blackwell. 166.

Halone, K. K., \& Billings, A. C. (2010). The temporal nature of racialized sport consumption. American Behavioral Scientist, 53(11), 1645-1668. doi:10.1177/0002764210368090

Harlow, S. (2013). It was a "Facebook revolution": Exploring the meme-like spread of narratives during the Egyptian protests. Fue una "Revolución de Facebook": Explorando la narrativa de los meme difundidos durante las protestas egipcias., 12, 59-82.

Hartmann, D. (2000). Rethinking the relationships between sport and race in American culture: Golden ghettos and contested terrain. Sociology Of Sport Journal, 17(3), 229-253. doi:10.1123/ssj.17.3.229

Hendricks, A., Kelley, J., Gordon, P., \& Foley, A. (2015). Citizen perceptions of police in the post-Ferguson era: A survey in partnership with the Richmond County Sheriff's office. Augusta, GA: CURS Summer Scholars Program at Georgia Regents University.

Hesse-Biber, S. N. (2010). Mixed methods research: Merging theory with practice. Thousand Oaks, CA: Guilford Press. 
Hovden, J. (2015). Assessing the sociology of sport: On sport organizations and neoliberal discourses. International Review for the Sociology of Sport, 50(4-5), 472-476. doi:10.1177/1012690214566645

Jones, J. (2015). In U.S., Confidence in police lowest in 22 years. Gallup. Retrieved from http://www.gallup.com/poll/ 183704/confidence-police-lowest-years.aspx

Keenan, T. (2014, September 13). The $\$ 45$ billion reason the NFL ignores despicable behavior. New York Post. Retreived from http://nypost.com/2014/09/13/the-business-behind-the-nfls-blind-side/

Knobel, M., \& Lankshear, C. (2007). A new literacies sampler. New York, NY: Peter Lang.

Lam, K. (2014) Quantifying Americans' mistrust of corporations. The Atlantic. Retrieved from http://www.theatlantic. com/business/archive/2014/09/quantifying-americans-distrust-of-corporations/380713/

McCann, M. (2016, January 17) Deflategate, one year later: The anatomy of a failed controversy. Sports Illustrated. Available online. https://www.si.com/nfl/2016/01/18/deflategate-one-year-later-tom-brady-bill-belichick.

Newburn, T. (2014, August 29) Civil unrest in Ferguson was fuelled by the Black community's already poor relationship with a highly militarized police force. LSE US Centre. Available online: https://blogs.lse.ac.uk/usapp blog/2014/08/29/civil-unrest-in-ferguson-was-fuelled-by-the-black-communitys-already-poor-relationship-with-ahighly-militarized-police-force/

Page, J. T., Duffy, M., Frisby, C., \& Perreault, G. (2016). Richard Sherman speaks and almost breaks the internet: Race, media, and football1. Howard Journal of Communications, 27(3), 270-289. doi:10.1080/10646175.2016.1176969

Page, J. T., \& Duffy, M. E. (2009). A battle of visions: Dueling images of morality in US political campaign TV ads. Communication, Culture \& Critique, 2(1), 110-135. doi:10.1111/j.1753-9137.2008.01031.x

Pew Research Center. (2015). Beyond distrust: How Americans view their government. Retrieved from http://www. people-press.org/2015/11/23/beyond-distrust-how-americans-view-their-government/

Rowe, D. (2007). Sports journalism still the toy department of the news media? Journalism, 8(4), 385-405. doi:10.1177/ 1464884907078657

Shifman, L. (2013). Memes in a digital world: Reconciling with a conceptual troublemaker. Journal of ComputerMediated Communication, 18, 362-377. doi:10.1111/jcc4.2013.18.issue-3

Shifman, L. (2014). Memes in digital culture. Cambridge, MA: MIT Press.

Southgate, D., Westoby, N., \& Page, G. (2010). Creative determinants of viral video viewing. International Journal of Advertising, 29, 2-14. doi:10.2501/S0265048710201221

Wann, D. L., \& Branscombe, N. R. (1995). Influence of identification with a sports team on objective knowledge and subjective beliefs. International Journal of Sport Psychology, 26(4), 551-567.

Wann, D. L., Peterson, R. R., Cothran, C., \& Dykes, M. (1999). Sport fan aggression and anonymity: The importance of team identification. Social Behavior and Personality: an International Journal, 27(6), 597-602. doi:10.2224/ sbp.1999.27.6.597

Wenner, L. A., \& Gantz, W. (1998). Watching sports on television: Audience experience, gender, fanship, and marriage. (Ed. Wenner, L.) MediaSport. New York, NY: Routledge: 233-251.

Wolff, H. A., Smith, C. E., \& Murray, H. A. (1934). The psychology of humor. The Journal of Abnormal and Social Psychology, 28(4), 341. doi:10.1037/h0075400

Yang, H. C., \& Wang, Y. (2015). Social sharing of online videos: Examining American consumers' video sharing attitudes, intent, and behavior. Psychology \& Marketing, 32(9), 907-919. doi:10.1002/mar.2015.32.issue-9

Zillmann, D., Bryant, J., \& Sapolsky, B. S. (1989). Enjoyment from sports spectatorship. Sports, Games, and Play: Social and Psychological Viewpoints, 2, 241-278.

Zillmann, D., \& Cantor, J. R. (1976). A disposition theory of humor and mirth. Humor and laughter: Theory, research, and application, 93-115

Zillmann, D., Paulus, P. B., \& Snyder, R. N. (1993). Handbook of research on sport psychology. New York, NY: Macmillan. 